\title{
How to Limit the Moral Hazard Related to a European Stabilization Mechanism
}

\author{
Séverine MENGUY \\ University of Paris $X$
}

\begin{abstract}
The paper studies the opportunity to introduce a centralized insurance mechanism in Europe. Indeed, in a monetary union, monetary policy can efficiently stabilize common shocks but it is much less usable in case of asymmetrical shocks and lor if the countries are structurally heterogeneous. Thus, the national and decentralized stabilization policies could be efficiently complemented by a global insurance mechanism. Indeed, introducing state dependent federal transfers is beneficial if the variance of demand or supply shocks is sufficiently high in comparison with the disincentive effect of these transfers on the national effort to reduce the variance of idiosyncratic shocks. Nevertheless, a state independent federal premium would then also be useful in order to avoid the moral hazard problem implied by a centralized insurance mechanism.
\end{abstract}

- JEL Classification: E63, H61, H77

- Key Words: Economic and Monetary Union, Fiscal Federalism, Stabilization policy, Insurance Mechanism

\section{Introduction}

In the literature about fiscal federalism, the question of the level at which the stabilization policy should be conducted is recurrent and has much been studied. Are regional and decentralized policies more efficient and more appropriate to

\footnotetext{
*Corresponding address: EconomiX. Bureau K123, Batiment K, Universite de Paris X -Nanterre, 200 Avenue de la Republique, 92001 Nanterre Cedex, France. E-mail: severine.menguy@orange. fr. Tel: (00 33) 140975914 .

(C2010-Center for International Economics, Sejong Institution, Sejong University, All Rights Reserved.
} 
fulfill this objective, or should the stabilization policy be centralized and delegated to the national level? Many theoretical studies have treated this question without succeeding to obtain clear-cut results. More recently, this interrogation has been extended to the framework of a monetary union. More precisely, the argument that the Economic and Monetary Union (EMU) would have to compensate for the loss of the exchange rate flexibility by a fiscal insurance mechanism has become very popular in the debate over monetary unification. Indeed, in federal States, the centralization of many pro-cyclical taxes (in particular income taxes) or contracyclical expenditures (unemployment benefits, social security) already provides automatically a high degree of economic stabilization. It is thus assumed that without a comparable degree of stabilization centrally provided, the success and the continued existence of the EMU could be endangered. Some monetary unions, as Switzerland, Belgium or Luxembourg, have succeeded to work without any federal budget responsible for the stabilization. However, in such small countries, the risks of large asymmetrical shocks, and thus the need for an insurance mechanism, were naturally much less important than in the current EMU...

Therefore, the opportunity to create a global and European stabilization mechanism has widely been analyzed in the economic literature. Many economists have proposed to create a budgetary mechanism of 'cyclical' transfers between the European countries [see for instance Sala-i-Martin and Sachs (1992), Italianer and Vanheukelen (1993), Von Hagen and Hammond (1998), etc.]. According to these authors, the global economic activity could be stabilized with the help of the common monetary policy, but the budgetary framework would be essential in stabilizing the differentials between the economic situations of the member countries. Indeed, a mechanism of cyclical and temporary transfers from the countries in a relatively good to those in a relatively bad cyclical economic situation would be useful to stabilize specific economic conditions, and it would facilitate the respect for the budgetary discipline as well as the fiscal convergence in the monetary union. In this literature, stabilization concerns the compensation of symmetrical or common shocks, which can already often be addressed by the common monetary policy. On the contrary, insurance concerns the compensation of asymmetrical or country-specific shocks, which becomes more complex in a monetary union (Eichengreen, 1993).

More precisely, in the framework of the creation of the EMU, many economic papers have been interested in studying stabilization and insurance policies in a monetary union. Indeed, with the suppression of exchange rate fluctuations, the 
interrogation was about the possibility to introduce other mechanisms to compensate for this loss of monetary autonomy. Federal and centralized fiscal transfers were then, naturally, the best candidates. For example, Farina and Tamborini (2001) find that in a monetary union, assigning the stabilization function to the monetary or fiscal authorities depends on the degree of correlation of shocks and on the respective width of the financial and budgetary externalities. However, the aim of the current paper is to study the conditions of efficiency of a centralized insurance mechanism given the optimal monetary policy of the central bank. Furthermore, even in federations, stabilization appears as only partial, and even quite weak, as a wide degree of stabilization would naturally imply non negligible incentive and moral hazard problems. Indeed, the asymmetry of information between the decentralized governments and the centralized authority is at the origin of a trade-off between the advantage of risk-sharing and the moral hazard problem. Without such a trade-off, fiscal federalism theories would automatically find that the centralization of all budgetary responsibilities is always favorable. This tradeoff, which implies that the optimal incentive mechanisms are not so self-evident, is thus very interesting to study. Therefore, beyond the theoretical arguments that have traditionally been mentioned in favor of a European stabilization mechanism, the current paper aims at analyzing the conditions of its efficiency, with regard to the moral hazard problem related to a centralized insurance mechanism.

The paper is organized as follows. The section II recalls the traditional arguments in favor of a European stabilization mechanism and the criteria that the latter should verify in order to be really efficient. Afterwards, the section III describes the macroeconomic model used to study the usefulness and the incentive efficiency of a centralized insurance mechanism. The section IV describes the stabilization that can be provided by the decentralized national budgetary policies, whereas the section $\mathrm{V}$ analyzes the conditions of efficiency of a global and centralized insurance mechanism. Finally, the section VI concludes.

\section{The Usefulness of a European Stabilization Mechanism}

\section{A. Arguments for a European Stabilization Mechanism}

Many arguments underline the necessity to put in place an efficient global insurance mechanism in the framework of the EMU, which could efficiently complement the stabilization provided by the national budgetary policies. Indeed, 
the loss of monetary autonomy in a monetary union, of the exchange rate policy and of the use of independent interest rates to stabilize asymmetrical shocks, plead for a more active use of the budgetary policies. However, emprically, econometrical studies have no clear-cut results regarding the degree of stabilization provided by the central government in federal States. Therefore, the degree of stabilization which is necessary to the well functioning of a monetary union remains ambiguous. Besides, in a federation, many shocks can already be absorbed with the help of pro-cyclical resources and contra-cyclical expenditures. On the contrary, the EU budget cannot play the same role today. Indeed, it would necessitate huge institutional changes, like the introduction of a supranational authority or the creation of real European taxes, for example. Thus, is the economic usefulness of the creation of a centralized European insurance mechanism worth the administrative and political costs of its introduction?

Forni and Reichlin (2001) show that Europe has a level of integration quite similar to the United-States'. Therefore, national shocks are not a sizeable source of fluctuations. The common European component explains the bulk of the output variance in Europe, except perhaps for Greece, Portugal and the United-Kingdom, which have large nation-specific dynamics. The economic frontiers of the shocks and of the asymmetries in the fluctuations are much more regional and inside the national boundaries than between the various European countries. Nevertheless, there are many arguments why a centralized European insurance mechanism could be very useful to the well functioning of the EMU. First, the mobility of the production factors (lending on the capital market, labor mobility) seems less efficient in Europe than in federal States to stabilize asymmetrical shocks. Besides, the stabilization policy can be decentralized and at the national level, but only if the automatic stabilizers are largely allowed to fluctuate, and if the budgetary policies are not too much constrained by rules like those of the Stability and Growth Pact or by the indebtedness of the countries. Furthermore, because of the openness of the European countries today, a purely national stabilization policy would be quite inefficient, as the budgetary multiplier would be small: the stabilization effort of each country would tend to remain inefficiently low and sub-optimal. Indeed, a national government can't then obtain any compensation for the benefices brought to other countries, whereas it must bear alone the budgetary costs of the stabilization, particularly in terms of increase in the debt. All governments have thus interest in a 'beggar the neighbor' policy.

Besides, a stabilization policy is always more efficient at the global level than at 
the level of each decentralized federated entity, as the decentralized stabilization by market mechanisms can only provide an intertemporal stabilization but no interregional insurance. Indeed, the contra-cyclical action of the national budgets provides the inhabitants of the European countries with a stabilization of their disposable income with the help of intertemporal transfers. The budgetary deficit of a country can increase in period of recession and decrease in period of growth; but the increase in deficits during a recession will constrain later this country to pay higher future taxes or to decrease its expenditures in order to reduce the deficit formerly created. On the contrary, an inter-regional insurance, which organizes a sharing of the risks to undergo economic fluctuations, can only be provided by the way of a supranational budget. Indeed, the stabilization then comes from interregional transfers that do not modify the budgetary equilibrium of the central federal authority. ${ }^{1}$

These arguments can explain why the McDougall Report (1977) already assessed that in Europe, a system of inter-country transfers was necessary to stabilize the asymmetrical shocks affecting the countries of the European Union. More precisely, it assessed that the EU budget should be increased to at least 5 to $7 \%$ of the Community GDP. Nevertheless, the main difficulty related to the introduction of a European insurance mechanism is the very weak level of political solidarity between the European countries. Furthermore, a centralized insurance policy could raise a more important moral hazard problem in Europe than in federations. Indeed, as political decisions remain fundamentally national in Europe, countries knowing that they could benefit from the Community financing may not fully internalize the recessive risks of their economic policies. Moreover, international agreements are much more fragile than those between private agents. Even in politically unified countries (Italy, Spain, Belgium), some citizens of the richest regions have underlined that their taxes contributed to finance high social transfers in the poorest regions, and they have thus spoken in favor of a system where regional taxes would finance regional transfers [see Artus (2003)]. Therefore, in these conditions, it is necessary to study which criteria a European stabilization mechanism should verify, in order to be really efficient and to avoid as much as possible the political and moral hazard problems.

${ }^{1}$ See Fatas (1998), for example, for a discussion and an illustration of this distinction between intertemporal stabilization and interregional insurance. 


\section{B. But the Necessity to Verify Efficiency Criteria}

First, the institution of an efficient European stabilization mechanism should overcome the constraints imposed by the current structure of the European budget. Indeed, the EU budget has today a very weak autonomy, as contributions from member States constitute its main resources, instead of federal taxes. Moreover, it represents only a small percentage of the Community GDP in comparison with the one of the federal States: it amounts to only $1.2 \%$ of the European Union GDP, i.e. to about $4 \%$ (against around $50 \%$ for the federal States) of the consolidated expenditures of all national European governments. Furthermore, whereas in the federal States, receipts and expenditures are quite flexible with conjunctural fluctuations, the European budget is very rigid: since 1988, it is regulated by 5 years long multi-annual agreements. Besides, about two thirds of this budget goes to the financing of the Common Agricultural Policy. The structure of the European budget is essentially dedicated to the functions of resources allocation and redistribution, and not the stabilization function. Furthermore, the EU budget must always be equilibrated, according to the lasting article 199 of the Rome Treaty. This prevents it from being efficient in the conjunctural stabilization, as empirically, an equilibrated budget generally implies pro-cyclical effects. Therefore, a priori, the European institutional framework doesn't seem well suited for a global and centralized stabilization policy. Nevertheless, what should be the criteria for an efficient European insurance mechanism?

Goodhart and Smith (1993) established some criteria to be enforced in order to obtain an efficient global stabilization policy. The stabilization must rely on automatic stabilizers, in order to avoid reaction delays which could make the contra-cyclical policy harmful. The transfers must be temporary to avoid moral hazard problems and long run redistributive effects. The transfer mechanism must rely on precise indicators, correctly reflecting movements of the conjunctural situation (unemployment, incomes), and it must only concern asymmetrical shocks specific to a given country. Furthermore, according to Von Hagen and Hammond (1998), the simplicity of the European stabilization mechanism must allow the agents to understand it and thus to accept it more easily. Besides, transfers paid and received from the insurance system must be null on average, along time and for each country: they mustn't derive in permanent redistributive flows. However, the authors show that the more simplified the transfer system administratively, the less efficient the stabilization. Indeed, in comparison with complex econometrical 
methods, transfers intended to stabilize annual real per head GDP growth rate around the European average would quickly become very large and would tend to derive in permanent redistributive flows. In this context, Italianer and Vanheukelen (1993) suggest, for example, the variations in unemployment rates as adjustment variable. ${ }^{2}$ They show the possibility to put in place in Europe a mechanism of efficient automatic interregional insurance, avoiding most of the moral hazard problems and of excesses in permanent redistributive flows, for a cost representing only $0.2 \%$ of the Community GDP. More recently, Bajo-Rubio and Díaz-Roldán (2003) propose a mechanism insuring the EMU countries against increases in their unemployment rates in comparison with monthly data of the preceding year. Another proposal by Melitz and Vori (1993) is to provide stabilization via transfers related to deviations of a country income per head from a national reference value. Nevertheless, as shocks on incomes among European countries are moderately persistent and positively correlated, the authors assume that the potential benefit of an insurance mechanism would then be small. In conclusion, the existing studies mostly assume that Europe could benefit from the creation of a revolving conjunctural stabilization Fund, representing a weak share (around $0.3 \%$ of GDP) of the budget voted by each country government, and which would be immediately activated to face asymmetrical shocks. However, a European insurance mechanism should respect some conditions in order to avoid the above mentioned negative incentive and moral hazard problems.

Regarding the EMU, Beetsma and Jensen (1999) also show that the Stability and Growth Pact can already introduce a kind of risk-sharing between the European countries. Indeed, the Pact would be counter-productive if by punishing a country in difficulty, it constrains this country to issue still more debt. But if the sanctions and the reference deficit level were contingent on the shock in a given country, the counter-productivity would be reduced. However, the authors also show that moral hazard reduces the attractiveness of making the sanctions contingent on the concrete economic situations of the countries, as relatively disciplined governments may then be worse off. The question is thus about the possibility to introduce a properly federal and centralized insurance mechanism in the EMU. So, Persson and Tabellini (1996) show, that centralizing tasks and powers from the local to the federal level is efficient under appropriate institutions. More precisely, federal risksharing can induce the local governments to enact policies that increase local risk.

${ }^{2}$ Unemployment rates have the advantage to be available with only small delays and to be sufficiently harmonized in Europe. 
However, the precedence in federal policy relative to local policy helps to reduce the incentive and moral hazard problems and to sustain a second best outcome in a non cooperative equilibrium, as the degree of risk-sharing is then more limited. In the same way, in the framework of a monetary union, Sanguinetti and Tomassi (2001) study the potential trade-off between providing centralized global insurance and providing adequate incentives for fiscal discipline and national effort. Then, they find that if the variance of local shocks is high, the central government should accommodate ex-post these shocks in order to provide the highest degree of full global insurance. On the contrary, if the number of sub-national governments (high level of decentralization) and if the common pool problem are high, the central government should better commit to provide limited ex-ante insurance. In the same tradition, our model aims at studying analytically the characteristics of an optimal European centralized insurance mechanism, which would take into account the moral hazard problem, i.e. which would solve the trade-off between providing a sufficient insurance and avoiding negative incentive effects.

\section{The Macroeconomic Model}

Artus (2003) expresses a negative opinion regarding the introduction of budgetary federalism in Europe. Indeed, in his model, regional or supra-national financings are equivalent regarding the consequences of transitory supply or demand shocks on employment: thus, a centralization of the insurance system would not be useful. Nevertheless, our analytical model can help to shed light on the usefulness of a global and centralized insurance mechanism in the European Union, in complement to national budgetary stabilization policies, as long as some conditions are verified in order to avoid the possible negative incentive effects and the moral hazard problem that such a mechanism could imply.

\section{A. The Basic Equations}

We use a simple static model of an open monetary union with two countries: $(i)$ and $(j)$. All variables are expressed in logarithms and in deviations from their long run equilibrium values. The demand function in the country $(i)$ is as follows:

$$
y_{i}^{d}=a_{i}\left(g_{i}+T_{i}\right)-b_{i}\left(r-p^{e}\right)+x_{i} y_{i}+x_{i}\left(p_{j}-p_{i}\right)+m_{i} y^{*}+m_{i}\left(p^{*}+e-p_{i}\right)+d_{i}
$$

with: in the country $i: y_{i}$ : economic activity; $g_{i}$ : public expenditures; $T_{i}$ : transfers 
from the federal government; $p_{i}$ : price level; $d_{i}$ : positive demand shock, which is a white noise $\left[\mathrm{E}\left(d_{i}\right)=0\right.$ and $\left.\mathrm{V}\left(d_{i}\right)=\sigma_{\mathrm{di}}{ }^{2}\right] ; r$ : common nominal interest rate; $p^{e}$ : anticipated average prices in the monetary union ${ }^{3} ; e$ : common exchange rate ( 1 unit of foreign $=\mathrm{e}$ units of common currency); $y^{*}$ : economic activity in the rest of the world; $p^{*}$ : prices in the rest of the world.

So, the demand in the country $i$ depends on the national or federal public expenditures, and it is also a decreasing function of the real interest rate. Furthermore, the net exports towards the other countries of the monetary union or the rest of the world are an increasing function of the domestic price competitiveness and of the foreign economic activity. Finally, the demand is also an increasing function of a positive demand shock. Studying demand shocks is very interesting, as the opportunity of the budgetary intervention in case of negative supply shocks is much more controversial. Indeed, there is then a trade-off between limiting the inflationary tensions and sustaining the economic activity: the best solution is thus often to let the central bank stabilize these shocks. Moreover, we aim at studying the sharing of responsibilities between the monetary and central or decentralized budgetary authorities even in the absence of conflict of interest regarding the inflation /economic activity trade-off characterizing supply shocks. Indeed, in our model, there is no 'inflation bias', as the economic authorities are only concerned with stabilizing the economic activity around its long run value, without being able and without trying to alter the long run levels of economic activity and employment (the potential output level).

Besides, the supply function in the country (i) is the following:

$$
y_{i}^{s}=z_{i}\left(p_{i}-p^{e}\right)+s_{i}
$$

where $s_{i}$ is a positive supply shock and a white noise $\left[\mathrm{E}\left(s_{i}\right)=0\right.$ and $\left.\mathrm{V}\left(s_{i}\right)=\sigma_{s i}{ }^{2}\right]$.

Therefore, in this traditional Lucas supply function, supply is an increasing function of the unexpected deviation of the national price level in comparison with the expected deviation of average prices in the whole monetary union. The supply is also an increasing function of a positive supply shock.

Furthermore, we make the hypothesis that the covariance between demand and supply shocks is null, but that each of them on their side can be more or less

$\overline{3}\left(r-p^{e}\right)$ can be considered as the real interest rate. Indeed, the monetary union is supposed to be at the equilibrium in the previous period. So, the average inflation rate in the current period is also the deviation of average prices from their long run values in the monetary union. 
correlated. So, if we suppose that $\left(-1<\rho_{\mathrm{ij}}<1\right)$ is the relation between demand shocks, we have: $\mathrm{d}_{\mathrm{j}}=\rho_{\mathrm{ij}} \mathrm{d}_{\mathrm{i}}$ (3).

- If $\rho_{\mathrm{ij}}=1$, the demand shock is symmetrical, and $\mathrm{d}_{\mathrm{i}}=\mathrm{d}_{\mathrm{j}}$.

- If $\rho_{\mathrm{ij}}=0$, a unilateral demand shock only affects one country; $\mathrm{d}_{\mathrm{j}}=0, \mathrm{~d}_{\mathrm{i}}>0$.

- If $\rho_{\mathrm{ij}}=-1$, there is a bilateral asymmetrical demand shock, and $\mathrm{d}_{\mathrm{i}}=-\mathrm{d}_{\mathrm{j}}$.

In the same way, if we suppose that $\left(-1<\varphi_{\mathrm{ij}}<1\right)$ is the relation between supply shocks, we have: $\mathrm{s}_{\mathrm{j}}=\varphi_{\mathrm{ij}} \mathrm{s}_{\mathrm{i}}$ (4).

Finally, the Uncovered real interest rate parity condition is the following:

$$
e=\left(r^{*}-p^{* e}\right)-\left(r-p^{e}\right)
$$

with: $r^{*}$ : foreign nominal interest rate; $p^{* e}$ : anticipated foreign price level.

Indeed, in the short run, the common exchange rate depreciates $(e>0)$ if the anticipated real interest rate increases in the rest of the world in comparison with the anticipated real interest rate in the monetary union, because of the immediate outgoings of capital.

\section{B. The Budgetary Reaction Functions}

Regarding the budgetary policies, we don't introduce any objective function, but we consider public expenditures functions that implicitly assume that the governments aim at minimizing variations in economic activity. So, we assume that there are two levels of decision. First, there is a national stage of fiscal policy:

$$
g_{i}=-f_{i} y_{i}+g_{0, i}
$$

Indeed, the automatic stabilizers are endogenous anti-cyclical budget adjustment mechanisms, and the budget $g_{i}$ of each country $i$ has an elasticity $f_{i}$ to economic fluctuations. Therefore, if $f_{i}$ is high, the government $i$ is lax: it stabilizes the national economic activity at the cost of a higher budgetary deficit. On the contrary, if $f_{i}$ is small, the government $i$ is virtuous: it controls its budgetary deficit but the economic stabilization remains limited. Furthermore, our model also allows for a discretionary national fiscal policy $g_{0, i}$, corresponding to an exogenous fiscal intervention (tax relief, extraordinary transfers, etc.).

Secondly, there is also a central or federal stage of budgetary policy. The transfer provided by the federal government to the country $i$ is the following:

$$
T_{i}=t\left(y_{j}-y_{i}\right)+I_{i}
$$


with $t$ : degree of insurance.

The first part, the cyclical transfer, is state dependent: the countries can be insured against a harmful deterioration of their own economic situation in comparison with the situation of the rest of the monetary union. These transfers can consist in either contributing less to the pro-cyclical resources financing the Community budget, or in receiving a higher part of the federal expenditures. They are by definition transitory, which also insures that the system is balanced on average over the business cycle. Besides, some countries are 'riskier' and have a higher probability to be affected by negative shocks. Therefore, the federal insurance mechanism should take this into account, and the riskiest countries should pay a premium to the less risky ones $I_{i}$, independently from their cyclical economic situation. Nevertheless, with Persson and Tabellini (1996), we can mention that such a premium could give rise to permanent redistributive flows, and could even be a source of conflict between the countries of the monetary union, each of them trying to exploit the system in order to obtain the highest state independent transfers. We will then try to define, in section 5, the optimal level of this premium $I$. In this paper, we also make the hypothesis that the country $i$ is less risky and receives $I_{i}=I$ whereas the country $j$ pays $I_{j}=-I$ to the federal government. The budgetary equilibrium of the insurance mechanism for the central authority is therefore verified, as: $T_{i}+T_{j}=I_{i}+I_{j}=0$.

\section{The Levels of Economic Activity and of Prices}

In the framework of the preceding equations, the economic authorities stabilize the economic variables and the consequences of the shocks without looking for affecting the long run and structural characteristics of the model. The common central bank aims at stabilizing average prices in the monetary union, and the optimal nominal interest rate $r$ verifies: $p=p^{\mathrm{e}}=0$. Therefore, we have the following levels of economic activity and of prices (see Appendix A):

$$
\begin{aligned}
& \phi p_{i}=\left(b_{j} m_{i}-b_{i} m_{j}\right)\left(p^{*}-p^{e *}+y^{*}+r^{*}\right)+\left[\left(b_{j}+m_{j}\right)-p_{i j}\left(b_{i}+m_{i}\right)\right] d_{i} \\
& +a_{i}\left(b_{j}+m_{j}\right) g_{o, j}-a_{j}\left(b_{i}+m_{i}\right) g_{o, j}+\left[a_{i}\left(b_{j}+m_{j}\right)+a_{j}\left(b_{i}+m_{i}\right)\right] l-\left\{\left(b_{j}+m_{j}\right)\right. \\
& \left.\left[\left(1+a_{i} f_{i}+a_{i} t\right)-\varphi_{i j}\left(x_{i}+a_{i} t\right)\right]-\left(b_{i}+m_{i}\right)\left[\varphi_{i j}\left(1+a_{j} f_{j}+a_{j} t\right)-\left(x_{j}+a_{j} t\right)\right]\right\} s_{i} \\
& \phi p_{j}=\left(b_{i} m_{j}-b_{j} m_{i}\right)\left(p^{*}-p^{e *}+y^{*}+r^{*}\right)-\left[\left(b_{j}+m_{j}\right)-p_{i j}\left(b_{i}+m_{i}\right)\right] d_{i} \\
& \text { - } a_{i}\left(b_{j}+m_{j}\right) g_{o, j}+a_{j}\left(b_{i}+m_{i}\right) g_{o, j}-\left[a_{i}\left(b_{j}+m_{j}\right)+a_{j}\left(b_{i}+m_{i}\right)\right] l+\left\{\left(b_{j}+m_{j}\right)\right. \\
& \left.\left[\left(1+a_{i} f_{i}+a_{i} t\right)-\varphi_{i j}\left(x_{i}+a_{i} t\right)\right]-\left(b_{i}+m_{i}\right)\left[\varphi_{i j}\left(1+a_{j} f_{j}+a_{j} t\right)-\left(x_{j}+a_{j} t\right)\right]\right\} s_{i}
\end{aligned}
$$




$$
\begin{aligned}
& \phi y_{i}=z_{i}\left(b_{j} m_{i}-b_{i} m_{j}\right)\left(p^{*}-p^{e *}+y^{*}+r^{*}\right)+z_{i}\left[\left(b_{j}+m_{j}\right)-p_{i j}\left(b_{i}+m_{i}\right)\right] d_{i} \\
& +a_{i} z_{i}\left(b_{j}+m_{j}\right) g_{o, j}-a_{j} z_{i}\left(b_{i}+m_{i}\right) g_{o, j}+z_{i}\left[a_{i}\left(b_{j}+m_{j}\right)+a_{j}\left(b_{i}+m_{i}\right)\right] l+K_{i} s_{i} \\
& \phi y_{i}=z_{j}\left(b_{i} m_{j}-b_{j} m_{i}\right)\left(p^{*}-p^{e *}+y^{*}+r^{*}\right)-z_{j}\left[\left(b_{j}+m_{j}\right)-p_{i j}\left(b_{i}+m_{i}\right)\right] d_{i} \\
& -a_{i} z_{j}\left(b_{j}+m_{j}\right) g_{o, j}+a_{j} z_{j}\left(b_{i}+m_{i}\right) g_{o, j}-z_{j}\left[a_{i}\left(b_{j}+m_{j}\right)+a_{j}\left(b_{i}+m_{i}\right)\right] l+\varphi_{i j} K_{j} s_{i} \\
& 2 \phi y=\left(z_{i}-z_{j}\right)\left(b_{j} m_{i}-b_{i} m_{j}\right)\left(p^{*}-p^{e *}+y^{*}+r^{*}\right)+\left(z_{i}-z_{j}\right)\left[\left(b_{j}+m_{j}\right)-p_{i j}\left(b_{i}+m_{i}\right)\right] d_{i} \\
& +a_{i}\left(z_{i}-z_{j}\right)\left(b_{j}+m_{j}\right) g_{o, i}-a_{j}\left(z_{i}-z_{j}\right)\left(b_{i}+m_{i}\right) g_{o, j}+\left(z_{i}-z_{j}\right)\left[a_{i}\left(b_{j}+m_{j}\right)+a_{j}\left(b_{i}+m_{i}\right)\right] l \\
& +\left(b_{j}+m_{j}\right)\left[\left(z_{j}+\varphi_{i j} z_{i}\right)\left(1+a_{i} f_{i}+2 a_{i} t+x_{i}\right)+\left(1+\varphi_{i j}\right)\left(2 x_{i}+m_{i}\right)\right] s_{i} \\
& +\left(b_{i}+m_{i}\right)\left[\left(z_{j}+\varphi_{i j} z_{i}\right)\left(1+a_{j} f_{j}+2 a_{j} t+x_{j}\right)+\left(1+\varphi_{i j}\right)\left(2 x_{j}+m_{j}\right)\right] s_{i} \\
& \phi=\left(b_{i}+m_{i}\right)\left[z_{j}\left(1+a_{j} f_{j}+a_{j} t\right)+z_{i}\left(x_{j}+a_{j} t\right)+2 x_{j}+m_{j}\right] \\
& +\left(b_{j}+m_{j}\right)\left[z_{i}\left(1+a_{j} f_{i}+a_{i} t\right)+z_{j}\left(x_{i}+a_{i} t\right)+2 x_{i}+m_{i}\right]>0 \\
& K_{i}=\left(b_{i}+m_{i}\right)\left[\left(z_{j}+\varphi_{i j} z_{i}\right)\left(1+a_{j} f_{j}+a_{j} t\right)+2 x_{j}+m_{j}\right] \\
& +\left(b_{j}+m_{j}\right)\left[\left(z_{j}+\varphi_{i j} z_{i}\right)\left(x_{i}+a_{i} t\right)+2 x_{i}+m_{i}\right]
\end{aligned}
$$

Thus, monetary policy can attenuate the consequences of demand and supply shocks but without fully compensating for their effects. For example, as in Farina and Tamborini (2001), in the presence of a positive demand shock in one country, the central bank should increase the interest rate in an extent proportional to the shock $\left(\mathrm{d}_{i}\right)$ and to its degree of correlation $\left(\rho_{i j}\right)$, and inversely proportional to the effect of the interest rate on aggregate demand [(B) in Appendix A]. However, even if the central bank can perfectly stabilize average prices, monetary policy cannot fully avoid the economic fluctuations in each particular country. The national (Section IV) or federal (Section V) budgetary policies can therefore also intervene in order to improve the economic stabilization in the monetary union.

\section{The Stabilization Provided by the National Policies}

With the financial and economic crisis of 2007-2009, all over the world, national governments have launched programs of public expenditures to sustain the economic activity, in a difficult global economic framework. This hard global context has thus made the question of activist fiscal policies quite topical again. So, what can do the decentralized and national stabilization policies of each government? In the simplest way, we make the hypothesis that each government tries to minimize deviations of income from its null and equilibrium value. The 
expected loss function of the country $(i)$ is therefore: $\mathrm{E}\left(L_{i}\right)=\mathrm{E}\left(y_{i}^{2}\right)=\operatorname{Var}\left(y_{i}\right)+\mathrm{E}\left(y_{i}\right)^{2}$. In this context, what are the economic consequences of demand or supply shocks, and what are then the appropriate national budgetary policies?

\section{A. The Demand Shocks}

In case of demand shocks or shocks in the rest of the world, prices and activity levels may vary if the countries of the monetary union are structurally heterogeneous, and/or if demand shocks are asymmetrical. More precisely, the common monetary policy can perfectly stabilize shocks in the rest of the world if and only if: $b_{j} m_{i}=b_{i} m_{j}$, and internal demand shocks if and only if: $b_{j}+m_{j}=\rho_{\mathrm{ij}}\left(b_{i}+m_{i}\right)$. So, in case of demand shocks, the economic stabilization in each country is improved with respect to the correlation of shocks, as the intervention of the central bank is then larger. Indeed, if the shocks are symmetrical $\left(\rho_{\mathrm{ij}}=1\right)$ and if the countries are homogeneous, the stabilization is perfect. On the contrary, with an asymmetrical bilateral shock $\left(\rho_{\mathrm{ij}}=-1\right)$, there is no variation in demand at the aggregate level, and thus, the variation in interest rates is negligible, as the country affected by the shock expands while the other country is in recession. Our result is thus in conformity with the traditional advise that the monetary authority should only stabilize symmetrical and common shocks.

In this framework, what can do the budgetary authorities to complement monetary policy in case of asymmetrical shocks, and/or if the countries are heterogeneous? If $f_{i}$ increases and if a country chooses to let the automatic stabilizers play more freely, or with a higher degree of federal insurance policy $(t)$, the impact of the shock is reduced ( $\phi$ increases). However, the automatic and 'endogenous' budgetary policies can't perfectly stabilize the economic variables in case of demand shocks, unless $\left(f_{i} \rightarrow \infty\right),\left(f_{j} \rightarrow \infty\right)$ or $(t \rightarrow \infty)$. In these conditions, discretionary national policies can also be useful; indeed, they can perfectly stabilize internal demand shocks if and only if:

$$
\begin{gathered}
g_{0, i}=\frac{-\left[\left(b_{j}+m_{j}\right)-p_{i j}\left(b_{i}+m_{i}\right)\right]}{a_{i}\left(b_{j}+m_{j}\right)} d_{i} \text { and } \\
g_{0, j}=\frac{-\left[\left(b_{i}+m_{i}\right)-p_{i j}\left(b_{j}+m_{j}\right)\right]}{a_{j}\left(b_{i}+m_{i}\right)} d_{j}
\end{gathered}
$$

In the same way, they can stabilize external shocks if and only if:

$$
g_{0, i}=\frac{\left(b_{i} m_{j}-b_{j} m_{i}\right)}{a_{i}\left(b_{j}+m_{j}\right)}\left(p^{*}-p e^{*}+y^{*}+r^{*}\right) \text { and }
$$




$$
g_{0, j}=\frac{\left(b_{j} m_{i}-b_{i} m_{j}\right)}{a_{j}\left(b_{i}+m_{i}\right)}\left(p^{*}-p e^{*}+y^{*}+r^{*}\right)
$$

Therefore, beyond the automatic stabilizers, the discretionary and contra-cyclical budgetary expenditures in the country $i$ should be a decreasing function of the correlation between demand shocks $\rho_{i j}$ and of the width of their repercussion in the monetary union. Indeed, the common monetary policy already stabilizes all the more these shocks as they are symmetrical. The necessary budgetary expenditures should also be a decreasing function of the sensibility of the activity to the national public expenditures $a_{i}$, as fiscal policies are then more efficient in influencing the economic activity. Furthermore, for positively correlated $\left(\rho_{i j}>0\right)$ internal demand shocks as well as positive external shocks, the supplementary budgetary expenditures in a given country $i$ should be an increasing function of the higher sensibility of its demand to the interest rate $\left(b_{i}>b_{j}\right)$, in order to compensate for the more recessive effect in this country of the contractionary monetary policy. Therefore, an important result of our study is that in order to respond to asymmetrical demand or external shocks, the coordination between the budgetary policies $\left(g_{0, i}\right.$ and $\left.g_{0, j}\right)$ of the national governments is essential... at least as long as there is no centralized insurance mechanism in the monetary union.

\section{B. The Supply Shocks}

Supply shocks are often linked to long run and structural policies; they have not only transitory but also long run consequences on the production level. Therefore, they are sometimes supposed to be excluded from stabilization policies. Nevertheless, what are their implications in the framework of our model? Supply shocks may increase the price differential between the countries of the monetary union if they are structurally heterogeneous and/or if the shocks are asymmetrical. Indeed, prices are stabilized in each country if and only if:

$$
0<\varphi_{i j}=\frac{\left[\left(b_{i}+m_{i}\right)\left(a_{j} t+x_{j}\right)+\left(b_{j}+m_{j}\right)\left(1+a_{i} f_{i}+a_{i} t\right)\right]}{\left[\left(b_{i}+m_{i}\right)\left(a_{i} t+x_{i}\right)+\left(b_{i}+m_{i}\right)\left(1+a_{j} f_{j}+a_{j} t\right)\right]}<1
$$

However, the central bank cannot avoid the higher economic growth in both countries in case of positively correlated supply shocks $\left(\varphi_{\mathrm{ij}}>0\right)$. Indeed, the global economic activity is stabilized if and only if:

$$
-1<\varphi_{i j}=\frac{\left[z_{j} k_{i j}+\left(b_{j}+m_{j}\right)\left(2 x_{i}+m_{i}\right)+\left(b_{i}+m_{i}\right)\left(2 x_{j}+m_{j}\right)\right]}{\left[z_{i} k_{i j}+\left(b_{j}+m_{j}\right)\left(2 x_{i}+m_{i}\right)+\left(b_{i}+m_{i}\right)\left(2 x_{j}+m_{j}\right)\right]}<0
$$




$$
k_{i j}=\left(b_{i}+m_{i}\right)\left(1+a_{j} f_{j}+2 a_{j} t+x_{j}\right)+\left(b_{j}+m_{j}\right)\left(1+a_{i} f_{i}+2 a_{i} t+x_{i}\right)>0
$$

Therefore, prices can only be stabilized in each country if supply shocks are positively correlated, as the decrease in interest rates then avoids the deflationary tensions in both countries. On the contrary, stabilizing the global economic activity is only possible for very asymmetrical supply shocks. In particular, if the countries have homogeneous supply functions and in case of asymmetrical bilateral supply shocks $\left(\varphi_{\mathrm{ij}}=-1\right.$ and $\left.z_{i}=z_{j}\right)$, the global economic activity can perfectly be stabilized. Indeed, the economic growth and the deflation in the country positively affected by the supply shock are then exactly compensated by the recession and the inflation in the partner country, with nearly no variation in interest rates. However, in most cases, monetary policy cannot fully stabilize supply shocks, and efficient national budgetary policies can then also be useful.

As for demand shocks, if $f_{i}$ increases with the automatic stabilizers, the impact of a supply shock on the national economic activity is only reduced ( $\phi$ increases). However, the discretionary budgetary policy in the country $i$ can perfectly stabilize the national economic activity if and only if:

$$
g_{0, i}=\frac{-K_{i}}{a_{i} z_{i}\left(b_{j}+m_{j}\right)} s_{i}
$$

So, the discretionary budgetary expenditures should be an increasing function of the sensibility of the national supply function to prices $z_{i}{ }^{4}$ Indeed, after a positive supply shock, the national budgetary policy can then be less contractionary, as monetary policy is less expansionary to reduce the deflationary tensions. On the contrary, these expenditures should be a decreasing function of the sensibility of the foreign supply function to prices $z_{j}$. Indeed, the higher deflationary tensions and gains in price-competitiveness for the national country increase the national exports, which necessitates a more contractionary budgetary policy. Finally, the discretionary budgetary expenditures should be a decreasing function of the openness of the countries within the monetary union $\left(x_{i}\right.$ and $\left.x_{j}\right)$, as pricecompetitiveness and activity differentials have then already a stabilizing effect on the respective economic activity levels in the monetary union. Regarding other parameters, everything depends on the degree of correlation between supply

$$
\frac{\partial g_{o, i}}{\partial z_{i}}=\frac{\left(b_{j}+m_{j}\right)\left[z_{j}\left(x_{i}+\alpha_{i} t\right)+2 x_{i}+m_{i}\right]+\left(b_{i}+m_{i}\right)\left[z_{j}\left(1+\alpha_{j} f_{j}+\alpha_{j} t\right)+2 x_{j}+m_{j}\right]}{\alpha_{i} z_{i}^{2}\left(b_{j}+m_{j}\right)}>0
$$


shocks. However, in case of positive supply shocks, the discretionary budgetary expenditures must always be a decreasing function of the correlation between supply shocks $\left(\varphi_{\mathrm{ij}}\right)$, as the common monetary policy is then already very expansionary to reduce the deflationary tensions.

\section{The Utility of a Centralized Insurance Mechanism}

We have seen in the preceding section that the discretionary national budgetary policies can be determined in order to perfectly stabilize specific demand or supply shocks. However, these budgetary policies can be more or less constrained, for example by the level of indebtedness of the countries or by the Stability and Growth Pact in Europe. Furthermore, the coordination between the national fiscal policies remains very limited and imperfect in Europe. Therefore, the introduction of a centralized insurance mechanism is often considered as very useful to respond to asymmetrical shocks, in the framework of a monetary union, as long as it avoids the moral hazard problem that, precisely, the Stability Pact intended to prevent. In the context of our model, what could then be the implications and the advantages of such a mechanism?

\section{A. The Cyclical or State Dependent Transfers $(t)$}

The introduction of a centralized insurance mechanism and an increase in $t$ reduces the variations in economic activity, in case of demand but also generally in case of supply shocks (see Appendix B). However, the countries must then arbitrate between a centralized insurance mechanism which improves the economic stabilization and the fact that transfers can have a disincentive effect on the national effort and on the variance of economic shocks. Everything then depends on the way the insurance mechanism interferes with the optimal policies of the governments at the national level. For example, Von Hagen and Wyplosz (2008) find that the effect of the fiscal insurance mechanism on the optimal regional policy depends on the effect of a region's variance on the variance of average income and on the degree of insurance already in place. To study this question, let us suppose that the variance of the national income depends on the centralized degree of insurance $t$. It is then plausible to assume that the derivatives of the variances of shocks with respect to $t$ are positive, as a centralized transfer mechanism reduces the national effort to limit the income variability. Thus, for demand shocks, the optimal degree of insurance is, for the country $i$ : 


$$
\begin{gathered}
t_{(i)}=R_{i}\left(b_{i}+m_{i}\right)\left[\left(z_{i}+z_{j}\right) a_{j} \sigma_{d i}-\left(\frac{\partial \sigma_{d i}}{\partial t}\right)\left(z_{j}+z_{j} a_{j} f_{j}+z_{i} x_{j}+2 x_{j}+m_{j}\right)\right] \\
+R_{i}\left(b_{j}+m_{j}\right)\left[\left(z_{i}+z_{j}\right) a_{i} \sigma_{d i}-\left(\frac{\partial \sigma_{d i}}{\partial t}\right)\left(z_{i}+z_{i} a_{i} f_{i}+z_{j} x_{i}+2 x_{i}+m_{i}\right)\right] \\
R_{i}=1 /\left(\frac{\partial \sigma_{d i}}{\partial t}\right)\left(z_{i}+z_{j}\right)\left[a_{i}\left(b_{j}+m_{j}\right)+a_{j}\left(b_{i}+m_{i}\right)\right]>0
\end{gathered}
$$

For each country $i$, the optimal degree of insurance $t_{i}$ is thus an increasing function of the variance of its demand shocks $\sigma_{d i}{ }^{2}$ : the country with a higher instability always prefers larger transfers. Furthermore, it is a decreasing function of the disincentive effect of the transfers on the national effort to reduce the economic instability $\left(\partial \sigma_{\mathrm{di}} / \partial \mathrm{t}>0\right)$. The optimal degree of centralized insurance is also a decreasing function of the flexibility of the national automatic stabilizers $f_{i}$ and $f_{j}$, as both instruments can be substitutable. It is a decreasing function of the openness of the countries within the monetary union $x_{i}$ and $x_{j}$, as economic activity differentials then tend to be automatically reduced by the effect of pricecompetitiveness or activity differentials on the exports. The optimal degree of insurance is also generally an increasing function of the sensibility of the supply functions to prices $z_{i}$ and $z_{j}$, as variations in economic activity are then accentuated. Finally, it is an increasing function of the efficiency of the budgetary policies to affect national demands $a_{i}$ and $a_{j}$ (see Appendix B).

Regarding supply shocks, the situation is more difficult to solve analytically. Nevertheless, everything depends on the relative values of the variance of supply shocks and of the disincentive effect of a transfer mechanism on the national effort to reduce this variance (see Appendix B). Indeed, if the variance of supply shocks $\left(\sigma_{\mathrm{si}}^{2}\right)$ is very high, a centralized transfer mechanism can be beneficial. On the contrary, if the disincentive effect of this transfer mechanism on the national effort to reduce the economic instability is high $\left(\partial \sigma_{\mathrm{si}} / \partial \mathrm{t}>0\right)$, introducing such a mechanism could only be detrimental.

\section{B. The Introduction of a State Independent Premium (I)}

We have just seen that the desired degree of insurance $(t)$ for the centralized policy can differ between the member countries of a monetary union. Furthermore, a centralized insurance mechanism can have a disincentive effect on the national effort to reduce the variability of the economic activity. Therefore, in parallel to this centralized policy, the introduction of a state independent premium could be 
beneficial. Such a premium could incite the countries to reduce their exposure to risks, and it could reduce the moral hazard problem implied by a centralized transfer policy. Indeed, without such a premium, the countries could be tempted to limit their own stabilization effort, to rely on the federal transfers to stabilize their own economic activity, and even to take too many risks. So, if the countries are heterogeneous and/or if the shocks are asymmetrical, a federal insurance policy and state dependent transfers $(t>0)$ should be combined with a state independent premium $(I>0)$ inciting the countries to conduct the appropriate national budgetary policies.

In the framework of our model, even if the shocks are white noises and exogenous, the central authority can influence a country's risk exposure and the variance of the shocks with such a premium. So, for demand shocks, the optimal premium from the viewpoint of the country $i$, which verifies $\partial \mathrm{E}\left(L_{i}\right) / \partial I=0$, is then:

$$
I_{(i)}=\frac{\left[\left(b_{j}+m_{j}\right)-\varphi_{i j}\left(b_{i}+m_{i}\right)\right]^{2} \sigma_{d i}}{\left[a_{i}\left(b_{j}+m_{j}\right)+a_{j}\left(b_{i}+m_{i}\right)\right]^{2}}\left(-\frac{\partial \sigma_{d i}}{\partial I}\right)
$$

Regarding supply shocks, this optimal premium is the following:

$$
I_{(i)}=\frac{K_{i}^{2} \sigma_{d i}}{z_{i}^{2}\left[a_{i}\left(b_{j}+m_{j}\right)+a_{j}\left(b_{i}+m_{i}\right)\right]^{2}}\left(-\frac{\partial \sigma_{d i}}{\partial I}\right)
$$

It is plausible to assume that the derivatives of the variances relative to (I) are negative, as this premium aims at encouraging the national stabilization effort of the countries. So, in both cases, the federal premium should be an increasing function of its efficiency in reducing the variance of demand or supply shocks, and in inciting the countries to reduce their exposure to risks $\left(-\partial \sigma_{\mathrm{si}} / \partial I>0\right)$. It should also be an increasing function of the variance of shocks $\left(\partial \sigma_{\mathrm{di}}{ }^{2}\right.$ or $\left.\partial_{\mathrm{si}}{ }^{2}\right)$, i.e. of the economic uncertainty in the monetary union. Furthermore, for demand or not excessively asymmetrical supply shocks, ${ }^{5}$ the premium should be a decreasing function of the sensibility of the demand to the public expenditures $\left(a_{i}\right.$ and $\left.a_{j}\right)$.

Besides, for intermediary values of our parameters $\left[\operatorname{Max}\left(-\frac{a_{i}}{a_{j}} ;-\frac{a_{j}}{a_{i}}\right)<\rho_{i j}<\operatorname{Min}\left(\frac{b_{i}+m_{i}}{b_{j}+m_{j}} ; \frac{b_{j}+m_{j}}{b_{i}+m_{i}}\right)\right]$, the optimal premium should be a decreasing function of the correlation between demand shocks $\left[\partial I / \partial \rho_{\mathrm{ij}}<0\right]$. Indeed, ${ }^{5}$ The precise condition is : $\varphi_{\mathrm{ij}}>\operatorname{Max}\left(\left(-\frac{z_{i}}{z_{j}} ;-\frac{z_{j}}{z_{i}}\right)\right.$, which insures that: $\frac{\partial I_{(i)}}{\partial a_{i}}<0, \frac{\partial I_{(i)}}{\partial a_{j}}<0, \frac{\partial I_{(j)}}{\partial a_{i}}<0$ and
$\frac{\partial I_{(j)}}{\partial a_{j}}<0$ according to Appendix C. 
the more asymmetrical demand shocks are, the more the premium must incite the countries to conduct active national budgetary policies, as monetary policy is then less efficient in stabilizing the situation of each particular country. On the contrary, the premium should be an increasing function of the correlation between supply shocks $\left[\partial \mathrm{I} / \partial \varphi_{\mathrm{ij}}<0\right]$. Indeed, if supply shocks are highly correlated, monetary policy is more active to stabilize prices, which has the same destabilizing effect on the level of economic activity in each country. Therefore, a centralized state independent premium should incite the countries to conduct the contra-cyclical budgetary policies necessary to reduce the economic fluctuations. Furthermore, for demand shocks, the desired premium is also generally an increasing function of the parameters (b) and ( $\mathrm{m}$ ) in the foreign country and a decreasing function of these parameters in the national country $\left[\frac{\partial I_{(i)}}{\partial b_{i}}=\frac{\partial I_{(i)}}{\partial m_{j}}>0>0\right.$ and $\frac{\partial I_{(i)}}{\partial b_{i}}=\frac{\partial I_{(i)}}{\partial m_{i}}<0$ if $-\frac{a_{j}}{a_{i}}<\rho_{i j}<\frac{b_{j}+m_{j}}{b_{i}+m_{j}}$; see Appendix C]. Indeed, the country which has the lowest sensibilities of its demand to the interest rate or to the exports towards the rest of the world is favorable to the introduction of such a premium: as variations in economic activity are more limited in this country, it is less risky, and it would thus be the beneficiary of the premium. Nevertheless, concerning these structural parameters, the analytical results are more ambiguous for supply shocks.

Moreover, regarding supply shocks, the federal premium should be generally an increasing function of the use of the national or centralized automatic stabilizers $\left[\frac{\partial I}{\partial f_{i}}>0, \frac{\partial I}{\partial f_{i}}>0\right.$ and $\frac{\partial I}{\partial t}>0$ if $\left.\left.\varphi_{\mathrm{ij}}>\operatorname{Max}\left(-\frac{z_{i}}{z_{j}} ;-\frac{z_{j}}{z_{i}}\right)\right)\right]$. Indeed, the budgetary authorities must all the more be incited to be virtuous as they conduct active policies. The premium aiming at encouraging virtuous national behaviors should also be an increasing function of the openness of the countries within the monetary union $\left[\frac{\partial I}{\partial x_{i}}>0\right.$ and $\left.\frac{\partial I}{\partial x_{i}}>0\right]$, as price competitiveness and activity differentials have then more extensive destabilizing effects. Finally, regarding supply shocks, the desired premium should also be mostly an increasing function of the parameter (z) in the foreign country and a decreasing function of this parameter in the national country $\left[\frac{\partial I_{(i)}}{\partial z_{i}}>0\right.$ and $\frac{\partial I_{(i)}}{\partial z_{i}}<0$; see Appendix C]. Indeed, the country with the lowest sensibility of its supply function to prices is favorable to the introduction of such a premium: as variations in economic activity are more limited in this country, it is less risky, and it would thus be the beneficiary of the premium.

\section{Conclusion}

The stabilization and insurance functions that the budgetary authorities should 
provide have been largely studied, in a federal context and in the framework of a monetary union, and more recently in the new context of the EMU in Europe. So, traditionally, it appears that monetary policy can efficiently contribute to the stabilization of common shocks, but that it is much less usable in case of asymmetrical shocks and /or if the countries are structurally heterogeneous. Thus, in this case, the stabilization provided by active budgetary policies is often considered as very useful. First, our model shows that the decentralized stabilization policies and the national automatic stabilizers can reduce the fluctuations in economic activity and in prices. However, discretionary national expenditures are also generally necessary to allow for a more accomplished economic stabilization. These supplementary budgetary expenditures should be an increasing function of the correlation between positive demand shocks but a decreasing function of the correlation between positive supply shocks.

Nevertheless, to compensate for insufficiently coordinated or hardly constrained national budgetary policies, a global and centralized stabilization mechanism would also be very useful to the European framework. Indeed, introducing state dependent federal transfers is beneficial if the variance of demand or supply shocks is sufficiently high in comparison with the disincentive effect of such a centralized transfer mechanism on the national effort to reduce the variance of idiosyncratic shocks. However, a state independent federal premium should then efficiently complement such a mechanism, in order to incite the countries to be virtuous and to conduct the appropriate national budgetary policies, i.e. in order to avoid the moral hazard problem implied by a centralized insurance mechanism. Such a premium should be an increasing function of its efficiency in reducing the variance of demand or supply shocks, of the variance of shocks, and of the correlation between supply shocks. On the contrary, it should be a decreasing function of the correlation between demand shocks, and of the sensibility of the demand to the public expenditures. Our paper is therefore in conformity with the numerous studies stressing the usefulness of the introduction of a global insurance mechanism in Europe. However, beyond this result, it also gives interesting indications regarding the complementary incentives that could help to reduce the moral hazard problem related to any global and centralized insurance mechanism.

\section{Acknowledgements}

I would like to thank the participants to the EconomiX seminars and the 
anonymous referee of the Journal of Economic Integration for their helpful comments. Naturally, I am alone responsible for the errors and omissions that could remain in this paper.

Received 5 February 2010, Revised 3 April 2010, Accepted 6 April 2010

\section{References}

Artus, P. (2003), "Faut-il un Mécanisme Fiscal d'Assurance dans une Union Monétaire?", Revue Economique, 54 (2), mars, pp. 253-270.

Bajo-.Rubio, O., Díaz-Roldán, C. (2003), "Insurance Mechanisms against Asymmetric Shocks in a Monetary Union: A Proposal with an Application to EMU”, Louvain Economic Review, 69(1), pp. 73-96.

Beetsma, R.M.W.J., Jensen, H. (1999), "Risk Sharing and Moral Hazard with a Stability Pact". Center for Economic Policy Research, Discussion Paper No. 2167.

Eichengreen, B. (1993), "European Monetary Unification", Journal of Economic Literature, Vol. 31, pp. 1321-1357.

Farina, F., Tamborini, R. (2001), "Macroeconomic Stabilization Policies in Europe under the New Regime of Monetary Union”. Working paper No. 137, Universita degli studi di Siena.

Fatas, A. (1998), “Does EMU Need a Fiscal Federation?”, Economic Policy, Vol.13, No. 26, pp. 163-203.

Forni, M., Reichlin, L. (2001), "Federal Policies and Local Economies: Europe and the US”, European Economic Review, Vol. 45, pp. 109-134.

Goodhart, C. A., Smith, S. (1993), "Stabilization", European Economy, The Economics of Community Public Finance, No. 5, pp. 417-456.

Italianer, A., Vanheukelen, M. (1993), "Proposals for a Community Stabilization Mechanism: Some Historical Applications", European Economy, The Economics of Community Public Finance, No. 5, pp. 493-510.

MacDougall Report (1977), Report on the Study Group of Public Finance in European Integration. Office des publications officielles des Communautés européennes, Luxembourg.

Melitz, J., Vori, S. (1993), "National Insurance against Unevenly Distributed Shocks in a European Monetary Union", Recherches Economiques de Louvain, 59 (1-2), pp.81104.

Persson, T., Tabellini, G. (1996), "Federal Fiscal Constitutions: Risk Sharing and Moral Hazard", Econometrica, Vol. 64, pp. 623-46.

Sala-i-Martin, X., Sachs, J. (1992), "Fiscal Federalism and Optimum Currency Areas: Evidence for Europe from the United States", In: Canzoneri, M. B., Grilli, V. and Masson, P. R. (eds), Establishing a Central Bank: Issues in Europe and Lessons from the U.S, Cambridge, pp. 195-221. 
Sanguinetti, P., Tomassi, M. (2001), "Inter-governmental Transfers and Fiscal Behavior: Insurance Versus Aggregate Discipline", Working Paper, Torcuato Di Tella University, Buenos Aires.

Von Hagen, J., Hammond G.W. (1998), "Regional Insurance against Asymmetric Shocks: An Empirical Study for the European Community", The Manchester School of Economic and Social Studies, 66 (3), June, pp. 331-353.

Von Hagen, J., Wyplosz, C. (2008), "EMU's Decentralized System of Fiscal Policy", European Economy, Economic Papers No. 306, February.

\section{Appendix}

\section{A. Prices and activity}

By combining equations (1) to (7), the output market equilibrium in each country $\left(\mathrm{y}_{\mathrm{i}}^{\mathrm{d}}=\mathrm{y}_{\mathrm{i}}^{\mathrm{s}}\right)$, and using $\left(\mathrm{d}_{\mathrm{i}}=\rho_{\mathrm{ij}}{ }^{2} \mathrm{~d}_{\mathrm{i}}\right)$ and $\left(\mathrm{s}_{\mathrm{i}}=\varphi_{\mathrm{ij}}{ }^{2} \mathrm{~s}_{\mathrm{i}}\right)$, we have:

$$
\begin{aligned}
A p_{i}= & -B_{i} r+C_{i}\left(p^{*}-p^{e *}+y^{*}+r^{*}\right)+D_{i} d_{i}+E_{i} p^{e}+F_{i}\left(g_{0, i}+I\right)+G_{i}\left(g_{0, j}-I\right)-H_{i} s_{i} \\
A= & {\left[z_{i}\left(1+a_{j} f_{i}+a_{i} t\right)+x_{i}+m_{i}\right]\left[z_{j}\left(1+a_{j} f_{j}+a_{j} t\right)+x_{j}+m_{j}\right] } \\
& -\left[z_{j}\left(x_{i}+a_{i} t\right)+x_{i}\right]\left[z_{i}\left(x_{j}+a_{j} t\right)+x_{j}\right]>0 \\
B_{i}= & \left(b_{i}+m_{i}\right)\left[z_{j}\left(1+a_{j} f_{j}+a_{j} t\right)+x_{j}+m_{j}\right]+\left(b_{j}+m_{j}\right)\left[z_{j}\left(x_{i}+a_{i} t\right)+x_{i}\right]>0 \\
C_{i}= & m_{i}\left[z_{j}\left(1+a_{j} f_{j}+a_{j} t\right)+x_{j}+m_{j}\right]+m_{j}\left[z_{j}\left(x_{i}+a_{i} t\right)+x_{i}\right]>0 \\
D_{i}= & z_{j}\left(1+a_{j} f_{j}+a_{j} t\right)+x_{j}+m_{j}+z_{j}\left(x_{i}+a_{i} t\right) \rho_{i j}+x_{i} \rho_{i j}>0 \\
E_{i}= & {\left[z_{i}\left(1+a_{j} f_{i}+a_{i} t\right)+x_{i}+m_{i}+b_{i}\right]\left[z_{j}\left(1+a_{j} f_{j}+a_{j} t\right)+x_{j}+m_{j}\right] } \\
& -\left[z_{j}\left(x_{i}+a_{i} t\right)+x_{i}\right]\left[z_{i}\left(x_{j}+a_{j} t\right)+x_{j}-b_{i}\right] \\
F_{i}= & a_{i}\left[z_{j}\left(1+a_{j} f_{j}+a_{j} t\right)+x_{j}+m_{j}\right]>0 \\
G_{i}= & a_{j}\left[z_{j}\left(x_{i}+a_{i} t\right)+x_{i}\right]>0 \\
H_{i}= & z_{j}\left[\left(1+a_{j} f_{i}+a_{i} t\right)\left(1+a_{j} f_{j}+a_{j} t\right)-\left(x_{i}+a_{i} t\right)\left(x_{j}+a_{j} t\right)\right]+x_{i}\left[\left(1+a_{j} f_{i}+a_{i} t\right) \varphi_{i j}\right. \\
& \left.-\left(x_{j}+a_{j} t\right)\right]+\left(x_{j}+m_{j}\right)\left[\left(1+a_{j} f_{i}+a_{i} t\right)-\left(x_{i}+a_{i} t\right) \varphi_{i j}\right]
\end{aligned}
$$

The optimal interest rate, which verifies: $\mathrm{p}=\mathrm{p}^{\mathrm{e}}=0$, is thus as follows:

$$
\begin{aligned}
\left(B_{i}+B_{j}\right) r= & \left(C_{i}+C_{j}\right)\left(p^{*}-p^{e *}+y^{*}+r^{*}\right)+\left(D_{i}+\rho_{i j} D_{j}\right) d_{i}+\left(F_{i}+G_{j}\right)\left(g_{0, j}+I\right)+ \\
& \left(F_{j}+G_{i}\right)\left(g_{0, j}+I\right)-\left(H_{i}+H_{j} \rho_{i j}\right) s_{i}
\end{aligned}
$$

Therefore, we have:

$$
\begin{aligned}
\left(B_{i}+B_{j}\right) p_{i}= & \frac{\left(B_{j} C_{i}-B_{i} C_{j}\right)}{A}\left(p^{*}-p e^{*}+y^{*}+r^{*}\right)+\frac{\left(B_{j} D_{i}-\rho_{i j} B_{i} C_{j}\right)}{A} d_{i} \\
& +\frac{\left(B_{j} F_{i}-B_{i} G_{j}\right)}{A}\left(g_{0, i}+I\right)-\frac{\left(B_{i} F_{j}-B_{j} G_{i}\right)}{A}\left(g_{0, j}+I\right)
\end{aligned}
$$




$$
-\frac{\left(B_{j} H_{i}-\varphi_{i j} B_{i} H_{j}\right)}{A} s_{i}
$$

Then, the necessary calculations give the expression mentioned in equation (8).

\section{B. Centralized Transfer Policy}

If we assume that $\left(\mathrm{y}^{*}+\mathrm{r}^{*}\right)=\mathrm{g}_{0, \mathrm{i}}=\mathrm{g}_{0, \mathrm{j}}=0$,

$$
\begin{aligned}
\phi^{2} E\left(L_{i}\right)= & z_{i}^{2}\left[\left(b_{j}+m_{j}\right)-\rho_{i j}\left(b_{i}+m_{i}\right)\right]^{2} \sigma_{d i}^{2}+K_{i}^{2} \sigma_{s i}^{2} \\
& +z_{i}^{2}\left[a_{i}\left(b_{j}+m_{j}\right)+a_{j}\left(b_{i}+m_{i}\right)\right]^{2} I^{2}
\end{aligned}
$$

For demand shocks, to find $\left(\mathrm{t}_{(\mathrm{i})}\right)$, we solve:

$$
\begin{aligned}
& \frac{\partial E\left(L_{i}\right)}{\partial t}=\frac{2 z_{i}^{2}\left[\left(b_{j}+m_{j}\right)-\rho_{i j}\left(b_{i}+m_{i}\right)\right]^{2} \sigma_{d i}}{\phi^{3}}\left(\sigma_{d i} \frac{\partial \phi}{\partial t}-\phi \frac{\partial \sigma_{d i}}{\partial t}\right)=0 \\
& \frac{\partial t_{(i)}}{\partial z_{i}}=\frac{\left(b_{i}+m_{i}\right)\left(x_{j}+m_{j}+z_{i} x_{j}+z_{j}+z_{j} a_{j} f_{j}\right)+\left(b_{j}+m_{j}\right)\left(2 x_{i}+m_{i}+z_{j} x_{i}-z_{j}-z_{j} a_{j} f_{i}\right)}{\left(z_{i}+z_{j}\right)^{2}\left[a_{i}\left(b_{j}+m_{j}\right)+a_{j}\left(b_{i}+m_{i}\right)\right]} \\
& \frac{\partial t_{(i)}}{\partial a_{i}}=\frac{\left(b_{j}+m_{j}\right)\left[\left(b_{i}+m_{i}\right)\left(2 x_{j}+m_{j}+z_{i} x_{j}+z_{j}+z_{j} a_{j} f_{j}-z_{i} a_{j} f_{i}\right)+\left(b_{j}+m_{j}\right)\left(2 x_{i}+m_{i}+z_{j} x_{i}+z_{i}\right)\right]}{\left(z_{i}+z_{j}\right)\left[a_{i}\left(b_{j}+m_{j}\right)+a_{j}\left(b_{i}+m_{i}\right)\right]^{2}}
\end{aligned}
$$

For supply shocks, we have:

$$
\begin{aligned}
\frac{\partial E\left(L_{i}\right)}{\partial t} & =\frac{-2 K_{i} \sigma_{s i}}{\phi^{3}}\left(K_{i} \sigma_{s i} \frac{\partial \phi}{\partial t}-\phi \sigma_{s i} \frac{\partial K_{i}}{\partial t}-\phi K_{i} \frac{\partial \sigma_{d i}}{\partial t}\right) \\
= & \frac{2 K_{i}^{2} \sigma_{s i}}{\phi^{2}}\left(\frac{\partial \sigma_{d i}}{\partial t}\right)-\frac{2 K_{i} z_{i} \sigma_{s i}^{2}}{\phi^{3}}\left[a_{i}\left(b_{j}+m_{j}\right)+a_{j}\left(b_{i}+m_{i}\right)\right] \\
& \left\{\left(b_{i}+m_{i}\right)\left[\left(1-\varphi_{i j}\right)\left(2 x_{j}+m_{j}\right)+\left(\varphi_{i j} z_{i}+z_{j}\right)\left(1+a_{j} f_{i}-x_{j}\right)\right]\right. \\
& \left.+\left(b_{j}+m_{j}\right)\left[\left(1-\varphi_{i j}\right)\left(2 x_{i}+m_{i}\right)-\left(\varphi_{i j} z_{i}+z_{j}\right)\left(1+a_{i} f_{i}-x_{i}\right)\right]\right\}
\end{aligned}
$$

\section{The optimal premium (I)}

For demand shocks, we find:

$$
\frac{\partial I_{(i)}}{\partial b_{j}}=\frac{\partial I_{(i)}}{\partial m_{j}}=\left(\rho_{i j} a_{i}+a_{j}\right)\left(b_{i}+m_{i}\right) I_{d}
$$




$$
\begin{aligned}
& \frac{\partial I_{(i)}}{\partial b_{i}}=\frac{\partial I_{(i)}}{\partial m_{i}}=-\left(\rho_{i j} a_{i}+a_{j}\right)\left(b_{j}+m_{j}\right) I_{d} \\
& \frac{\partial I_{(i)}}{\partial \rho_{i j}}=-\left(b_{i}+m_{i}\right)\left[a_{i}\left(b_{j}+m_{j}\right)+a_{j}\left(b_{i}+m_{i}\right)\right] I_{d} \\
& \text { with } I_{d}=\frac{2\left[\left(b_{j}+m_{j}\right)-\rho_{i j}\left(b_{i}+m_{i}\right)\right] \sigma_{d i}\left(-\frac{\partial \sigma_{d i}}{\partial I}\right)}{\left[a_{i}\left(b_{j}+m_{j}\right)+a_{j}\left(b_{i}+m_{i}\right)\right]^{3}}
\end{aligned}
$$

$I f-1<\rho_{i j}<\frac{-a_{j}}{a_{i}}$, then $\frac{\partial I_{(i)}}{\partial b_{j}}=\frac{\partial I_{(i)}}{\partial m_{j}}<0, \frac{\partial I_{(i)}}{\partial b_{i}}=\frac{\partial I_{(i)}}{\partial m_{i}}>0$ and $\frac{\partial I_{(i)}}{\partial \rho_{i j}}<0$

If $\frac{-a_{j}}{a_{i}}<\rho_{i j}<\frac{\left(b_{j}+m_{j}\right)}{\left(b_{i}+m_{i}\right)}$, then $\frac{\partial I_{(i)}}{\partial b_{j}}=\frac{\partial I_{(i)}}{\partial m_{j}}>0, \frac{\partial I_{(i)}}{\partial b_{i}}=\frac{\partial I_{(i)}}{\partial m_{i}}<0$ and $\frac{\partial I_{(i)}}{\partial \rho_{i j}}<0$

$I f \frac{\left(b_{j}+m_{j}\right)}{\left(b_{i}+m_{i}\right)}<\rho_{i j}<1$, than $\frac{\partial I_{(i)}}{\partial b_{j}}=\frac{\partial I_{(i)}}{\partial m_{j}}<0, \frac{\partial I_{i}}{\partial b_{i}}=\frac{\partial I_{(i)}}{\partial m_{i}}>0$ and $\frac{\partial I_{(i)}}{\partial \rho_{i j}}>0$

For supply shocks, we find:

$$
\begin{aligned}
\frac{\partial I_{(i)}}{\partial a_{i}}= & -z_{i}\left(b_{j}+m_{j}\right)\left[\left(b_{j}+m_{j}\right)\left(2 x_{i}+m_{i}+x_{i} \varphi_{i j} z_{i}+x_{i} z_{j}\right)\right. \\
& \left.+\left(b_{i}+m_{i}\right)\left(\varphi_{i j} z_{j}+z_{j}\right)\left(1+a_{j} f_{j}\right)+\left(b_{i}+m_{i}\right)\left(2 x_{j}+m_{j}\right)\right] I_{s} \\
\frac{\partial I_{(i)}}{\partial a_{j}}= & -z_{i}\left(b_{i}+m_{i}\right)\left[\left(b_{j}+m_{j}\right)\left(2 x_{i}+m_{i}\right)+\left(b_{j}+m_{j}\right)\left(\varphi_{i j} z_{i}+z_{j}\right)\left(x_{i}-a_{j} f_{j}\right)\right] \\
& \left.+\left(b_{i}+m_{i}\right)\left(\varphi_{i j} z_{j}+z_{j}+2 x_{j}+m_{j}\right)\right] I_{s} \\
\frac{\partial I_{(i)}}{\partial z_{i}}= & -\left[a_{i}\left(b_{j}+m_{j}\right)+a_{j}\left(b_{i}+m_{i}\right)\right]\left[\left(b_{j}+m_{j}\right)\left(2 x_{i}+m_{i}+x_{i} z_{j}+z_{j} a_{i} t\right)\right] \\
& \left.+\left(b_{i}+m_{i}\right) z_{j}\left(1+a_{j} f_{i}+a_{i} t\right)+\left(b_{i}+m_{i}\right)\left(2 x_{j}+m_{j}\right)\right] I_{s} \\
\text { with } I_{s}= & \frac{2 \sigma_{s i}\left(-\frac{\partial \sigma_{s i}}{\partial I}\right) K_{i}}{z_{i}^{3}\left[a_{i}\left(b_{j}+m_{j}\right)+a_{j}\left(b_{i}+m_{i}\right)\right]^{3}}
\end{aligned}
$$

